www.nature.com/ja

\title{
Antitrypanosomal peptaibiotics, trichosporins B-VIla and B-VIIb, produced by Trichoderma polysporum FKI-4452
}

\author{
Masato Iwatsuki ${ }^{1}$, Yuta Kinoshita ${ }^{2}$, Megumi Niitsuma ${ }^{1}$, Junko Hashida ${ }^{1}$, Mihoko Mori ${ }^{2,3}$, Aki Ishiyama ${ }^{1}$, \\ Miyuki Namatame ${ }^{1}$, Aki Nishihara-Tsukashima ${ }^{1}$, Kenichi Nonaka ${ }^{3}$, Rokuro Masuma ${ }^{2,3}$, Kazuhiko Otoguro ${ }^{1}$, \\ Haruki Yamada $^{2,3}$, Kazuro Shiomi ${ }^{2,3}$ and Satoshi Ōmura ${ }^{3}$
}

The Journal of Antibiotics (2010) 63, 331-333; doi:10.1038/ja.2010.41; published online 30 April 2010

Keywords: antitrypanosomal; peptaibiotics; trichosporin

In the course of screening for new antitrypanosomal agents, several novel bioactive natural compounds have been discovered and reported by our group. ${ }^{1-3}$ Recently, we have isolated two new trichosporin analogs, designated as trichosporins B-VIIa (1) and B-VIIb (2), together with five known trichosporins $(3-7),{ }^{4}$ from the culture broth of Trichoderma sp. FKI-4452. These have proved to exhibit antitrypanosomal activity (Figure 1). In this paper, the fermentation, isolation, structure elucidation and biological activity of these novel trichosporins are described.

Fungal strain FKI-4452 was isolated from a soil sample collected in Yakushima-Island, Kagoshima, Japan by the dilution plating method. The ITS sequence of strain FKI-4452 was determined and deposited at the DNA Data Bank of Japan, with the accession number AB517619, using The TrichOKEY program of ITSH (International Subcommission on Trichoderma and Hypocrea Taxonomy), which suggested that the strain FKI-4452 belongs to Trichoderma polysporum. ${ }^{5}$ Moreover, FKI-4452 was a $98 \%$ match to the nucleotide sequences of T. polysporum CBS 820.68 according to the TrichoBLAST database of ITSH. ${ }^{5}$ Thus, the strain FKI-4452 was identified as T. polysporum and designated Trichoderma polysporum FKI-4452. There was no report of trichosporin production by T. polysporum CBS 820.68.

The strain FKI-4452 was grown and maintained on an LcA agar slant consisting of $0.1 \%$ glycerol, $0.08 \% \mathrm{KH}_{2} \mathrm{PO}_{4}, 0.02 \% \mathrm{~K}_{2} \mathrm{HPO}_{4}$, $0.02 \% \mathrm{MgSO}_{4} \cdot 7 \mathrm{H}_{2} \mathrm{O}, 0.02 \% \mathrm{KCl}, 0.2 \% \mathrm{NaNO}_{3}, 0.02 \%$ yeast extract and $1.5 \%$ agar (adjusted to $\mathrm{pH} 6.0$ before sterilization). A loop of spores of Trichoderma sp. FKI-4452 was inoculated into $100 \mathrm{ml}$ of the seed medium, which consisted of $2.0 \%$ glucose, $0.2 \%$ yeast extract, 0.5\% Polypepton (Wako Pure Chemical Industries, Osaka, Japan), $0.05 \% \mathrm{MgSO}_{4} \cdot 7 \mathrm{H}_{2} \mathrm{O}, 0.1 \% \mathrm{KH}_{2} \mathrm{PO}_{4}$ and $0.1 \%$ agar (adjusted to $\mathrm{pH}$
6.0 before sterilization), in a 500-ml Erlenmeyer flask. The inoculated flask was incubated in a rotary shaker $\left(210\right.$ r.p.m.) at $27{ }^{\circ} \mathrm{C}$ for 3 days.

For production of 1, 2, and the other known trichosporins (3-7), a $1-\mathrm{ml}$ portion of the seed culture was transferred to each of nine $500-\mathrm{ml}$ Erlenmeyer flasks containing $100 \mathrm{ml}$ of the production medium, consisting of $3.0 \%$ soluble starch, $2.0 \%$ soybean meal, $1.0 \%$ glycerol, $0.3 \%$ dry yeast, $0.3 \% \mathrm{KCl}, 0.2 \% \mathrm{CaCO}_{3}, \quad 0.05 \%$ $\mathrm{MgSO}_{4} \cdot 7 \mathrm{H}_{2} \mathrm{O}$, and $0.05 \% \mathrm{KH}_{2} \mathrm{PO}_{4}$ (adjusted to $\mathrm{pH} 6.5$ before sterilization), fermentation taking place on a rotary shaker (210 r.p.m.) at $27^{\circ} \mathrm{C}$ for 6 days.

To the whole culture broth (1.0l) was added 1.01 of ethanol, followed by filtration. The filtrate was concentrated under reduced pressure to remove ethanol and then extracted with 1.01 of ethyl acetate ( $\mathrm{pH} 2)$. The ethyl acetate layer was concentrated under reduced pressure to afford a crude extract $(745 \mathrm{mg})$. The ethyl acetate extract (426 mg) was applied to an ODS column (Pegasil Prep ODS-7515$12 \mathrm{~A}, 20 \phi \times 120 \mathrm{~mm}$, Senshu Scientific Co., Tokyo, Japan) pre-equilibrated with $20 \%$ methanol. The column was eluted with 20,40 and $60 \%$ methanol stepwise $(120 \mathrm{ml}$ each $)$ and the active principles were eluted with $80 \%$ methanol $(120 \mathrm{ml})$, followed by concentration in vacuo to yield a brown material $(91.0 \mathrm{mg})$. The material was purified by HPLC using a Pegasil ODS column $(20 \phi \times 250 \mathrm{~mm}$, Senshu Scientific Co.) with $70 \% \mathrm{CH}_{3} \mathrm{CN}$ at $5 \mathrm{ml} \mathrm{min}^{-1}$ detected at $\mathrm{UV}$ $210 \mathrm{~nm}$. The retention times of the active fractions $1,2,3$, and 4 were $16,18,20$, and $24 \mathrm{~min}$, respectively. The active fractions 1 and 2 were concentrated in vacuo to dryness to afford trichosporins B-V (3, $9.9 \mathrm{mg})$ and B-VIb $(4,10.0 \mathrm{mg})$, respectively, as white powders. The active fraction $3(8.4 \mathrm{mg})$ was purified by HPLC using an XBridge C8 column $(10 \phi \times 250 \mathrm{~mm}$, Waters Co., Milford, MA, USA) with $50 \%$

${ }^{1}$ Research Center for Tropical Diseases, Kitasato Institute for Life Sciences, Kitasato University, Tokyo, Japan; ${ }^{2}$ Graduate School of Infection Control Sciences, Kitasato University, Tokyo, Japan and ${ }^{3}$ Kitasato Institute for Life Sciences, Kitasato University, Tokyo, Japan

Correspondence: Professor K Shiomi, Kitasato Institute for Life Sciences and Graduate School of Infection Control Sciences, Kitasato University, 5-9-1 Shirokane, Minato-ku, Tokyo 108-8641, Japan.

E-mail: shiomi@lisci.kitasato-u.ac.jp

Received 27 January 2010; revised 3 April 2010; accepted 5 April 2010; published online 30 April 2010 
<smiles>[Y]C(=O)[C@H](C)NC(=O)C(C)(C)NC(C)=O</smiles>

\begin{tabular}{cccc}
\hline & X & Y & Z \\
\hline Trichosporin B-VIla (1) & Aib & L-lle & L-Iva \\
Trichosporin B-VIIb (2) & Aib & L-Leu & Aib \\
\hdashline Trichosporin B-V (3) & L-Ala & L-Ile & Aib \\
Trichosporin B-VIb (4) & L-Ala & L-lle & L-lva \\
Trichosporin B-Vla (5) & Aib & L-lle & Aib \\
Trichosporin B-IIla (6) & L-Ala & L-Leu & Aib \\
Trichosporin B-IVb (7) & L-Ala & L-Leu & L-lva \\
\hline
\end{tabular}

Figure 1 Structures of trichosporins B-VIIa (1) and B-VIIb (2) and other known trichosporins isolated (3-7).

$\mathrm{CH}_{3} \mathrm{CN}$ at $2.5 \mathrm{mlmin}^{-1}$ and was detected at $\mathrm{UV} 210 \mathrm{~nm}$. The retention times of the active fractions 3-1 and 3-2 were 30 and $35 \mathrm{~min}$, respectively. They were concentrated in vacuo to dryness to afford trichosporins B-VIa $(5,3.7 \mathrm{mg})$ and B-IIIa $(6,3.0 \mathrm{mg})$, respectively, as white powders. The active fraction $4(9.8 \mathrm{mg})$ was purified by HPLC using an XBridge C8 column (under the same conditions as described above). The retention times of the active fractions 4-1, 4-2 and 4-3 were 38,41 and $44 \mathrm{~min}$, respectively. They were concentrated in vacuo to dryness to afford $\mathbf{1}(2.2 \mathrm{mg})$, trichosporin B-IVb (7, $2.0 \mathrm{mg})$ and $2(0.8 \mathrm{mg})$, respectively, as white powders.

Compounds 1 and 2 showed strong IR absorptions at $3340(\mathrm{NH})$ and $1630(C=\mathrm{O}) \mathrm{cm}^{-1}$, which are characteristic of peptide bonds. The molecular weights of 1 and 2 were elucidated by ESI-MS to be 1978 and 1964, respectively. Analysis of their ${ }^{1} \mathrm{H}$ NMR spectra revealed the presence of an acetyl methyl group at $\delta_{\mathrm{H}} 2.1$, a phenyl group of phenylalaninol (Pheol) residue at $\delta_{\mathrm{H}} 7.1-7.4, \alpha$-proton methine signals of amino acid residues at $\delta_{\mathrm{H}} 4.0-5.5$, and some singlet methyl groups of $\alpha$-aminoisobutylic acid (Aib) residues at $\delta_{\mathrm{H}}$ 1.5-1.6. Thus, 1 and 2 were considered to belong to the peptaibiotic family. ${ }^{6}$

The amino-acid composition and their absolute configurations in $\mathbf{1}$ were elucidated as Gly, L-Ala, Aib, L-Pro, L-Val, L-isovaline (L-Iva), LLeu, L-Ile and L-Gln/Glu by HPLC analysis of its hydrolysate using a chiral column (Sumichiral OA-5000 $(4.6 \phi \times 150 \mathrm{~mm}), 2 \mathrm{mM} \mathrm{CuSO}_{4}$, $1.0 \mathrm{ml} \mathrm{min}-1$, UV $\left.254 \mathrm{~nm}, 40{ }^{\circ} \mathrm{C}\right) .^{7}$ The absolute configuration of phenylalaninol was not elucidated. The sequence of $\mathbf{1}$ was elucidated by FAB-MS fragmentation analysis. In FAB-MS analysis, the complementary fragment ions at $m / z 1191$ and 788 , which were considered to be formed from the entire molecule by cleavage of the labile peptide bond between Aib and Pro, ${ }^{8}$ were observed. The $\mathrm{m} / \mathrm{z} 1191$ ion generated fragment ions at $m / z 1106,993,936,851,738,525,440$, $355,284,199$ and 128, which were interpreted as the successive losses of Aib, Leu, Gly, Aib, Ile, Gln+Aib, Aib, Aib, Ala, Aib, Ala, and Ac-Aib, by comparison with other known trichosporins isolated. Conversely, the $m / z 788$ ion generated the fragment ions at $m / z 637,509,381,282$ and 197, which were interpreted as the successive losses of Pheol, Gln, Gln, Iva, Aib and Pro+Val. Based on the results mentioned above, the complete structure of $\mathbf{1}$ was elucidated to be Ac-Aib-Ala-Aib-AlaAib-Aib-Gln-Aib-Ile-Aib-Gly-Leu-Aib-Pro-Val-Aib-Iva-Gln-GlnPheol (Figure 1), representing a new analog of trichosporin B series. Therefore, we designated $\mathbf{1}$ as trichosporin B-VIIa.

The amino-acid composition and their absolute configurations in 2 were elucidated as Gly, L-Ala, Aib, L-Pro, L-Val, L-Leu and L-Gln/Glu by HPLC analysis of its hydrolysate using a chiral column. The sequence of 2 was elucidated by FAB-MS fragmentation analysis as for 1 . The complementary fragment ions at $m / z 1191$ and 774 , which were considered to be formed from the entire molecule by cleavage between Aib and Pro, were observed. The $m / z 1191$ ion generated the same fragment ions as 1, which suggested the successive losses of Aib, Leu, Gly, Aib, Leu, Gln+Aib, Aib, Aib, Ala, Aib, Ala and Ac-Aib. On the other hand, the $m / z 774$ ion generated the fragment ions at $m / z$ $623,495,367,282$ and 197, which were interpreted as the successive losses of Pheol, Gln, Gln, Aib, Aib and Pro+Val. Based on the results mentioned above, the complete structure of 2 was shown to be Ac-Aib-Ala-Aib-Ala-Aib-Aib-Gln-Aib-Leu-Aib-Gly-Leu-Aib-ProVal-Aib-Aib-Gln-Gln-Pheol (Figure 1), which was also a new analog and was named trichosporin B-VIIb. The other five known trichosporins were also identified, as shown in Figure 1, by the same procedure described above.

The antitrypanosomal activity of the compounds was measured using a method described previously. ${ }^{1}$ As shown in Table 1, all trichosporins showed antitrypanosomal activities against Trypanosoma brucei brucei strain GUTat 3.1. Among them, $\mathbf{5}$ showed the most potent activity, with an $\mathrm{IC}_{50}$ value of $0.16 \mu \mathrm{g} \mathrm{ml}^{-1}$ and the highest selectivity (cytotoxicity against MRC- 5 cells/antitrypanosomal activity) of 60 times. Compounds 1 and 2 showed moderate inhibitory activities, with $\mathrm{IC}_{50}$ values of 0.92 and $6.1 \mu \mathrm{g} \mathrm{ml}^{-1}$, respectively. There is no report of the antitrypanosomal activity of trichosporins. Trichosporins belong to the peptaibiotic family. Our group has previously reported that some peptaibiotics (leucinostatins and alamethicin I) exhibit antitrypanosomal activities. ${ }^{3}$ Therefore, trichosporins might have the same inhibitory mechanism, which is related to their membrane-interacting properties. Trichosporin B series has been 
Table 1 In vitro antitrypanosomal activity and cytotoxicity of trichosporins B-VIla (1) and B-VIIb (2) and other known trichosporins isolated (3-7)

\begin{tabular}{|c|c|c|c|}
\hline \multirow[b]{2}{*}{ Compound } & \multicolumn{2}{|c|}{$I_{50}\left(\mu g \mathrm{~m}^{-1}\right)$} & \multirow[b]{2}{*}{$\begin{array}{l}\text { Selectivity } \\
\text { index (SI) }\end{array}$} \\
\hline & $\begin{array}{c}\text { Anti-trypanosomal } \\
\text { activity (T. b. brucei } \\
\text { GUTat 3.1) }\end{array}$ & $\begin{array}{c}\text { Cytotoxicity } \\
\text { (MRC-5) }\end{array}$ & \\
\hline Trichosporin B-VIIa (1) & 0.92 & 13.3 & 14.4 \\
\hline Trichosporin B-VIIb (2) & 6.10 & 21.3 & 3.5 \\
\hline Trichosporin B-V (3) & 0.54 & 14.1 & 26.0 \\
\hline Trichosporin B-VIb (4) & 0.37 & 11.1 & 30.1 \\
\hline Trichosporin B-Vla (5) & 0.16 & 9.6 & 60.1 \\
\hline Trichosporin B-IIla (6) & 0.38 & 5.3 & 13.9 \\
\hline Trichosporin B-IVb (7) & 1.01 & 10.6 & 10.5 \\
\hline Suramin* & 1.58 & $>100$ & $>63$ \\
\hline
\end{tabular}

*Antitrypanosomal drug used clinically.

reported to uncouple the oxidative phosphorylation in rat liver mitochondria ${ }^{9}$ and form ion channels in lipid bilayer membranes. ${ }^{10}$

\section{ACKNOWLEDGEMENTS}

This study was supported, in part, by funds from the Drugs for Neglected Diseases initiative (DNDi), Quality Assurance Framework of Higher Education from the Ministry of Education, Culture, Sports, Science and Technology, Japan (MEXT), and the All Kitasato Project Study (AKPS). We are grateful to Ms Hitomi Sekiguchi and Mr Toshiaki Furusawa for their technical assistance and to Ms Akiko Nakagawa, Dr Kenichiro Nagai and Ms Noriko Sato, School of Pharmaceutical Sciences, Kitasato University for measurements of mass and NMR spectra.

1 Otoguro, K. et al. Selective and potent in vitro antitrypanosomal activities of 10 microbial metabolites. J. Antibiot. 61, 372-378 (2008).

2 Ishiyama, A. et al. In vitro and in vivo antitrypanosomal activities of two microbial metabolites, KS-505a and alazopeptin. J. Antibiot. 61, 627-632 (2008).

3 Ishiyama, A. et al. In vitro and in vivo antitrypanosomal activities of three peptide antibiotics: leucinostatin A and B, alamethicin I and tsuchimycin. J. Antibiot. 62, 303-308 (2009).

4 Fujita, T. et al. Structure elucidation of trichosporin-B-la, IIla, IIId and V from Trichoderma polysporum. J. Antibiot. 41, 814-818 (1988).

5 Druzhinina, I. et al. An oligonucleotide barcode for species identification on Trichoderma and Hypocrea. Fungal Genet. Biol. 42, 813-828 (2005).

6 Degenkolh, T., Kirschbaum, J. \& Bruckner, H New sequences, constituents, and producers of peptaibiotics: an update review. Chem. Biodivers. 6, 1052-1067 (2007).

7 Huang, Q. et al. Studies on metabolites of mycoparasitic fungi. II. Metabolites of Trichoderma koningii. Chem. Pharm. Bull. 42, 223-229 (1995).

8 Rebuffat, S., el Haiji, M., Henning, P., Davoust, D. \& Bodo, B. Isolation, sequence, and conformation of seven trichozianines B from Trichoderma harzianum. Int. J. Peptide Protein Res. 34, 200-210 (1989).

9 Okuda, M. et al. Fungal metabolites. X. The effect of peptide antibiotics, trichosporinBs, on the respiratory activity of mitochondria. Biol. Pharm. Bull. 17, 482-485 (1994).

10 Nagaoka, Y. et al. Role of proline residue in the channel-forming and catecholaminereleasing activities of the peptaibol, trichosporin-B-Vla. Biochim. Biophys. Acta 1283, 31-36 (1996) 